\title{
Diagnosis: Evolution
}

\author{
Thomas R. Meagher
}

Published online: 6 December 2011

(C) Springer Science+Business Media, LLC 2011

This special edition of Evolution: Education and Outreach features contributions to the annual Society for the Study of Evolution Education Symposium for 2011, "Evolutionary Medicine Symposium in Honor of George C. Williams." The many distinguished contributors to this symposium provided a detailed overview of the relevance of evolutionary biology to medical research and practice, drawing on the extended legacy of the vision of G.C. Williams. In addition to providing a broad overview of applications of evolutionary biology to medical science, publication of this symposium also provides an opportune moment to highlight the overall activities of the Education and Outreach Committee of the Society for the Study of Evolution (SSE) that sponsored this symposium.

The SSE Education Committee (renamed Education and Outreach by the SSE Council in 2011) was established in 1997 under the leadership of Dr. Irene Eckstrand (NIH), motivated by a perceived need to extend the SSE profile to encompass outreach, especially to K-12 educators. Following a challenge raised by Dr. Eckstrand at the SSE annual meeting in June of that year, the inaugural meeting of the SSE Education Committee took place at the NIH in November, 1997. That meeting included joint sessions with members of the National Science Teachers Association (NSTA) and the National Association of Biology Teachers (NABT). Those joint sessions were significant in several respects. First, they established the basis for what has been the ongoing emphasis of programs developed by the Committee: articulation of sound examples of evolutionary

T. R. Meagher $(\triangle)$

School of Biology, University of St Andrews,

Sir Harold Mitchell Building,

St. Andrews, Fife KY16 9TH, UK

e-mail: trm3@st-andrews.ac.uk biology and its applications that can be directly incorporated into the K-12 curricula. Second, the established connection with these educator-based societies led to presentations and workshops developed by SSE members for the annual meetings of the NSTA and the NABT. Sponsored workshops at education meetings soon grew to include annual meetings of the Society for the Advancement of Chicanos and Native Americans in Science. These workshops have now become part of the annual cycle of activities of the Committee.

Over the many years since its establishment, the SSE Education and Outreach Committee has broadened its scope to encompass a wide range of activities with strong support, both in spirit and in funding, from the SSE Council. The solid foundation for this Committee established by Dr. Eckstrand as chair from 1997 to 2001 has now been successfully carried forward and developed even further by a succession of chairs, including Dr. Sam Donovan (University of Pittsburgh), 2002-2004; Dr. Robert Pennock (Michigan State University), 2005-2010 and most recently Dr. Thomas Meagher (University of St. Andrews, UK), 2010-ongoing. The Committee engages in a number of partnerships with other organisations; recent examples include the Botanical Society of America (NSF sponsored PlantingScience teacher mentorship program), the Ecological Society of America (NSF sponsored Digital Resource Discovery [DRD] Project for development of online teaching resources), and various activities of the National Academy of Sciences on evolution education. The Committee participated in the first USA Science \& Engineering Festival (22-25 October 2010, Washington, D.C.) and has plans to participate in this festival in the future. In 2009, as part of the celebration of the Darwin Bicentennial, the Committee established what has become an annual small grants competition to encourage outreach by the SSE 
membership. These are just a few highlights of what the Committee hopes will continue to be a healthy diversity of outreach activities. One upcoming example is the integration of software modules developed by the DRD Project into the SSE website that will facilitate sharing of teaching modules and case studies in evolution, both for teacher outreach and for enrichment of undergraduate teaching.

The SSE Education and Outreach Committee also engages in a significant "inreach" to the SSE membership through an extensive series of activities at the annual meetings of the SSE. For example, at the most recent meeting of the SSE in June 2011, the Committee sponsored the following:

- A pre-conference EVO101 teacher workshop, featuring a session on the NIH/BSCS Evolutionary Medicine Module, organised by Dr. Louise Mead (BEACON, Michigan State University) and Dr. Kristin Jenkins (NESCent)

- An outreach workshop for SSE members emphasizing evolutionary medicine and organised by Dr. Mead and Dr. Jenkins

- The annual Stephen J. Gould prize, presented this year to Dr. Ken Miller (Brown University), which includes a lecture by the prize winner that is open to the general public

- An undergraduate diversity reception, organized by Dr. Scott Edwards (Harvard University), Dr. Jory Weintraub (NESCent) and Dr. Richard Kliman (Cedar Crest College, NJ) with support from the NSF, and finally

- The Evolutionary Medicine Symposium in honor of G. C. Williams, organised by Dr. Mike Antolin (Colorado State University) and Dr. Jenkins with support from NESCent, that is the subject of this special issue of Evolution: Education and Outreach.

The Committee was especially pleased to sponsor this symposium because evolutionary medicine provides such a useful framework for making evolutionary biology relevant to students. Examples of medical applications of evolutionary biology can be timely and indeed can build on headline news items. In recent years, evolutionary biology has played a significant role in medical forensics of HIV, tracking the vestiges of polio to facilitate vaccination initiatives, understanding of systemic diseases such as arthritis and obesity, understanding the origins of new diseases such as SARS or novel strains of existing diseases such as influenza and development of public health measures to control malaria, just to name a few examples. The use of web-based resources, such as the DRD project mentioned above, can facilitate circulation of such examples and case studies as they are developed to maintain topicality in real time.

The development of medical examples in teaching of evolution has many potential impacts. First, it introduces topicality into teaching at all levels. Second, as part of general undergraduate biology training, it contributes to understanding of underlying causality in human health that is important for future consumers of medicine. Finally, it has the potential to promote integration of evolutionary biology into medical training. The latter is of particular significance not only in terms of medical research but also medical practice. Evolutionary principles underlie many, perhaps all, aspects of human health. Moreover, the emphasis on hypothesis generation and testing of longterm causality that is part of evolutionary thinking has the potential to reinforce scientifically based diagnosis. The contributions to this issue demonstrate for a variety of audiences the compelling nature of the interconnections that exist between evolution and medicine.

A healthy dose of evolutionary biology should be just what the doctor orders! 